Indexed by

\title{
Scopus
}

\section{USING THE LINEAR DAMAGE SUMMATION HYPOTHESIS IN THE FATIGUE TESTS ANALYSIS OF TITANIUM ALLOY PIECES}

Crossref

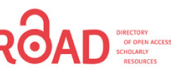

KOBSON

81 Google

\section{Evgeniya Gnatyuk}

Moscow Polytechnic University, Department of Dynamics, Strength and Resistance of Materials, Moscow, Russian Federation

\author{
Arkadiy Skvortsov \\ Moscow Polytechnic Univer- \\ sity, Department of Dynamics, \\ Strength and Resistance of \\ Materials, Moscow, Russian \\ Federation
}

\author{
Svetlana Kuleshova \\ Moscow Polytechnic Univer- \\ sity, Department of Dynamics, \\ Strength and Resistance of \\ Materials, Moscow, Russian \\ Federation
}

Key words: elastic deformation, high strength, fatigue tests, endurance limit, regression analysis doi:10.5937/jaes0-30915

Cite article:

Gnatyuk, E., Skvotsov, A., Kuleshova, S. (2021) USING THE LINEAR DAMAGE SUMMATION HYPOTHESIS IN THE FATIGUE TESTS ANALYSIS OF TITANIUM ALLOY PIECES, Journal of Applied Engineering Science, 19(3), 586-591, DOI:10.5937/jaes0-30915 


\title{
USING THE LINEAR DAMAGE SUMMATION HYPOTHESIS IN THE FATIGUE TESTS ANALYSIS OF TITANIUM ALLOY PIECES
}

\author{
Evgeniya Gnatyuk, Arkadiy Skvortsov, Svetlana Kuleshova \\ Moscow Polytechnic University, Department of Dynamics, Strength and Resistance of Materials, Moscow, \\ Russian Federation
}

This paper presents the results of fatigue tests of titanium alloy, and also describes the use of the hypothesis of linear damage summation when processing the results of fatigue tests. Based on the experiments, the endurance limit of the titanium alloy was determined, which lies in the range from 460 to $480 \mathrm{MPa}$ with the number of cycles from 105 to 108. The purpose of the experiment was to determine the endurance limit of high-strength material, as well as a mathematical measurement of the expected destruction. In this study, empirical methods were used such as indirect observation of the object under study, description, and measurement of technical influences exerted on it by an artificial means, as well as linear regression analysis to establish the relationship between stress and durability. As a result of the experiment, fatigue curves were obtained for various probabilities, which give grounds to conclude that the use of the linear damage summation hypothesis in processing the results of fatigue tests entails a satisfactory practical accuracy of the calculation of endurance limit. This experiment is aimed at improving metal production by studying the quality of titanium alloy test pieces and performing mathematical analysis of possible problems arising in the process of its operational testing.

Key words: elastic deformation, high strength, fatigue tests, endurance limit, regression analysis

\section{INTRODUCTION}

It is commonly known that under the action of cyclic stresses in metals and alloys, cracks appear and gradually develop, ultimately causing destruction. Such processes of gradual accumulation of damage under the influence of cyclic loads are called fatigue [1]. Fatigue fractures are especially dangerous in that they can develop under the action of stresses that are much lower than the ultimate strength and yield strength. It is noted that more than $80 \%$ of all cases of operational failure occur as a result of cyclic loading $[2,3]$. Due to the long duration, and, consequently, the high cost, fatigue tests to determine the endurance limit of samples are often carried out not until destruction, but for the determination of operating time, a certain test base $\mathrm{N}_{\mathrm{B}}$. In this case, the pieces that have passed the test without destruction are tested again at higher levels of vibration stresses [2-4]. As a rule, when conducting regression analysis of test results, specimens that failed during the test with operating time corresponding to $\mathrm{N}_{\mathrm{B}}$ are taken into account. In linear regression analysis to establish the relationship between stress and durability, it is necessary to transform the values to represent the equation of the fatigue curve as a linear relationship between the converted values $[5 ; 6]$. The following is usually taken as a random variable: $y=\lg N$, since it is in this case that the normal distribution law underlying the regression analysis is satisfactory. The transformed value $x=F(\sigma a)$ is selected as an independent value. The form of the function $x=F(\sigma a)$ is set so that the dependence $y=f(x)$ is linear [7-9]. The fatigue curve equation has the form:
$Y=a+b(x-\bar{x})$

where $x=\lg \sigma ; y=\lg N$; $a$ and $b-$ fatigue curve parameters. With an insufficient amount of fatigue tests, the parameters of equation (1) are determined based on regression analysis, i.e., the equation of the averaged fatigue curve corresponding to the fracture probability $P=0.5$ is established. With a sufficient amount of testing, a family of curves can be constructed for several fixed levels of fracture probabilities [10-12].

So, the purpose of the study is to conduct the investigation of the fatigue tests of titanium alloy, and also to describe the use of the hypothesis of linear damage summation when processing the results of fatigue tests. The research objectives are:

- to descript and measurement of technical influences exerted on the object by an artificial means;

- to conduct linear regression analysis to establish the relationship between stress and durability;

- to determine the endurance limit of high strength material, as well as a mathematical measurement of the expected destruction.

\section{MATERIALS AND METHODS}

For the experiments, an alloy of technical titanium was used, intended for the manufacture of products with high strength with sufficient plasticity and toughness, high resistance and small plastic deformations, brittle and fatigue fracture. The alloy under consideration is used in 
mechanical engineering, instrument manufacture, and the tool industry. The chemical composition of the alloy and its physicomechanical characteristics are presented in Table 1. Fatigue tests of the pieces were carried out by the well-known methods [1] on an electrodynamic shaker at normal temperature with cantilever mounting of the test piece (Fig. 1).

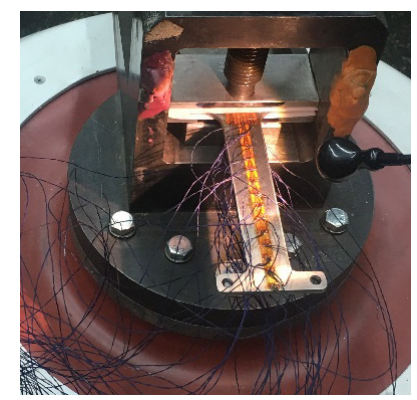

Figure 1: Photo of an electrodynamic shaker with a restrained test piece with strain gauges attached

It is known that the work of external forces applied in the process of elastic deformation is conserved as some energy, which then restores the element after the stress is removed. However, when a crack appears in the material, the number of elastic energy changes. If the elastic strain energy of a plate without a crack at a given stress level is equal to $U_{0}$, then in the presence of a crack it will be determined by the equation:

$U=U_{0}-\frac{1}{\varepsilon} \pi \alpha^{2} \sigma^{2}+4 \alpha T$

where $E$-elasticity modulus of the material.
The component $1 / E \pi a^{2} \sigma^{2}$ shows a decrease in the elastic strain energy of the plate due to the presence of a crack in it, $2 a$ is the crack length. This expression was obtained under the assumption that in the presence of a crack of size $2 a$ in the plate, the elastic energy of deformation is absent in the volume of the material equal to $\pi a^{2}$. The value $4 a T$-the surface energy of the crack, taking into account the formation of two surfaces; $T$-specific surface energy equal to the work required to form a unit area of the new surface. Initially, the total energy of the body increases with increasing crack length, which indicates that crack growth can occur only with increasing stresses. In this case, stable crack growth is observed. With an increase in the size of a crack to a certain critical size, the cracks grow due to the reserve of elastic energy without an additional increase in stresses [1].

Indeed, the results of the study showed that at a stress level of $\sigma_{0}=200 \mathrm{MPa}$ along bending and torsional forms, crack formation processes were detected in the materials under study. At the same time, at the moment of the appearance of a crack in the specimen, a decrease in the frequency of natural vibrations by $3 \%$ was noted. The mechanism of fatigue fracture is largely associated with the inhomogeneity of the real structure of materials (difference in size, shape, orientation of adjacent metal grains). The formation of cracks in the experiments began from the edge regions, which was confirmed by the results of scanning electron microscopic studies (Fig. 2). Next, analyze the fatigue curves for various fracture probabilities (Fig. 3).

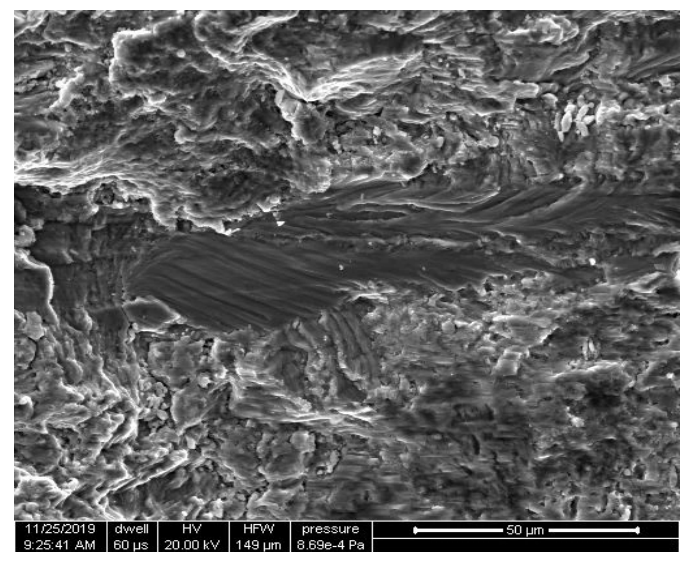

(a)

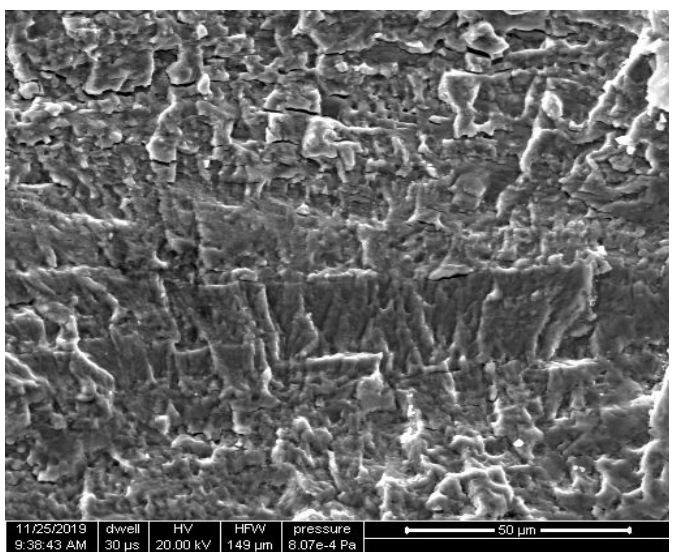

(b)

Figure 2: Photography of fractured surfaces of a test piece

Table 1: Chemical composition and physicomechanical characteristics of titanium alloy

\begin{tabular}{|c|c|c|c|c|c|c|c|}
\hline \multicolumn{8}{|c|}{ Chemical composition of Titanium alloy } \\
\hline Element & $\mathrm{Ti}$ & $\mathrm{Al}$ & $\mathrm{Fe}$ & $\mathrm{O}$ & $\mathrm{Si}$ & $\mathrm{C}$ & Other impurities \\
\hline Mass fraction, \% & 99.3 & 0.18 & 0.17 & 0.15 & 0.08 & 0.06 & 0.06 \\
\hline \multicolumn{7}{|c|}{ Physicomechanical characteristics } \\
\hline Characteristics & $\mathrm{E}$ & \multicolumn{2}{|c|}{$\sigma \mathrm{B}$} & $\delta \mathrm{B}$ & $\mathrm{HB}$ \\
\hline Value & $1.1 \mathrm{GPa}$ & $410 \mathrm{MPa}$ & $26 \%$ & $150 \mathrm{MPa}$ \\
\hline
\end{tabular}




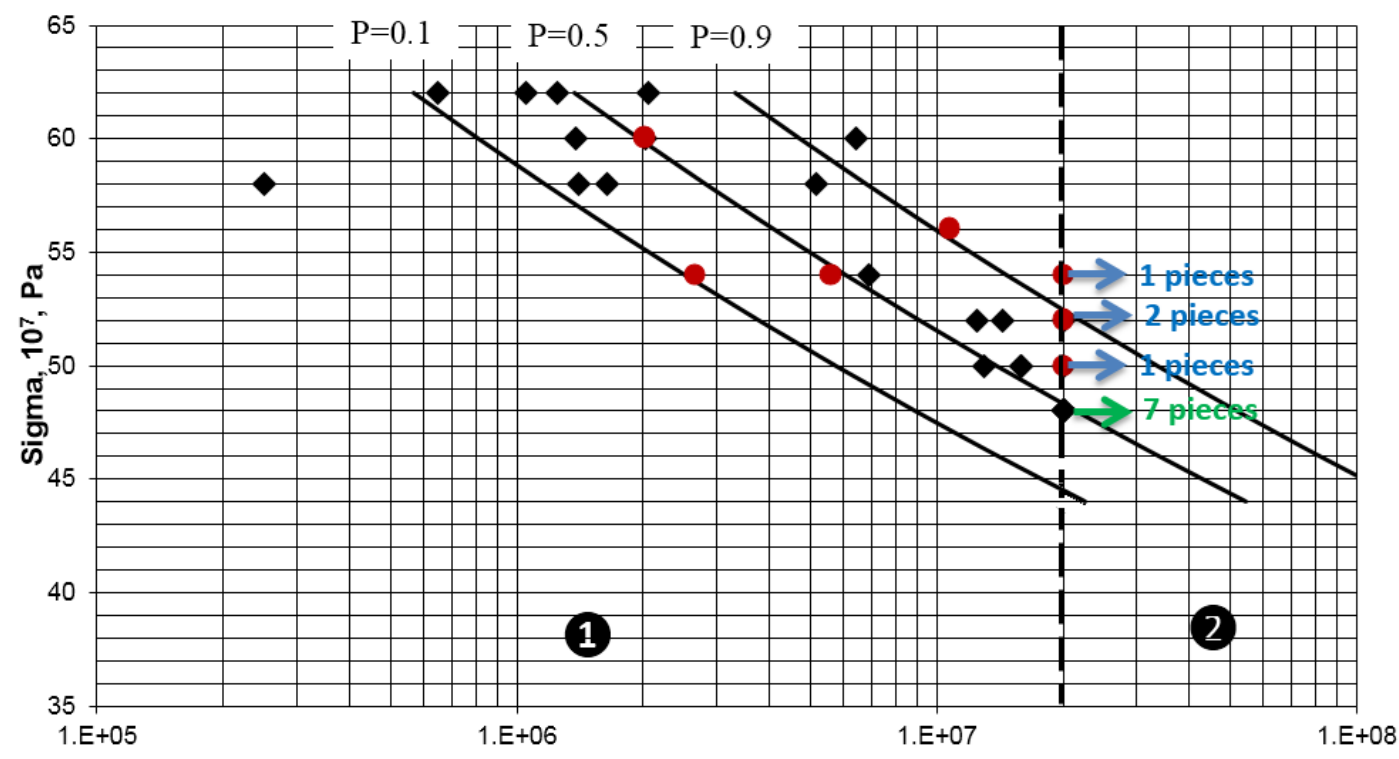

$\mathrm{N}$, number of cycles

Figure 3: Fatigue curves for different fracture probabilities $P(0.1 ; 0.5 ; 0.9)$

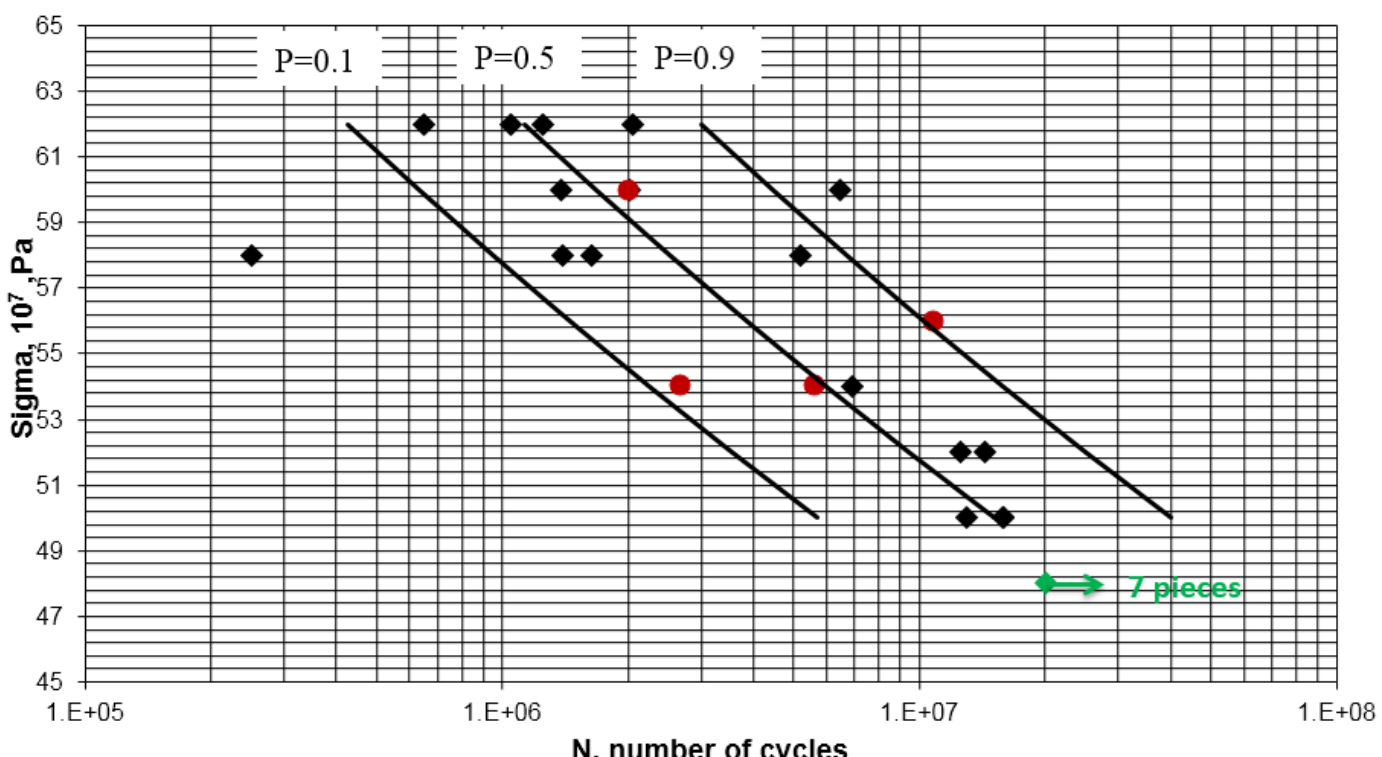

Figure 4: Fatigue curves for different fracture probabilities $P(0.1 ; 0.5 ; 0.9)$

For the endurance limit, a level of vibration stresses was taken at which from 6 to 8 pieces passed [13; 14]. As can be seen from Figure 3, with the previously used approach to processing the results of fatigue tests, the endurance limit (based on 7 samples) practically lies on the fatigue curve with a fracture probability $P=0.5$.

\section{RESULTS AND DISCUSSION}

In the present study, the authors have carried out mechanical tests of materials for high-cycle fatigue with the number of load cycles up to $106-108$. The amplitude for this type of test was selected in such a way that the material deformation occurred only in the elastic zone, and the stresses were less than the proportional elastic limit. The results of the study showed that the fatigue fracture observed in experiments has a complex development and depends on several factors (in our case, the composition and structure of the material, the load characteristics). Experiments have shown that, as expected, a feature of the fracture process under cyclic loading is the appearance of microcracks in the material (long before fracture). Such microcracks were formed on the surface of the material where the change of the shape took place. The test data will be processed in 3 stages. At the first stage, a regression analysis will be carried out, using only the durability at which the specimen fractured, the resulting fatigue curves are shown in Figure 4 . The points corresponding to the specimens tested at several load levels are highlighted in red; only the last level at which the failure occurred is taken into account. The green dots corresponding to the endurance limit are not included in the analysis.

At the second stage, recalculating the durability for pieces tested at several load levels, using the linear sum- 
mation of damage accumulated at each load level [15]. At each i-th load level, after the number of cycles $n_{i}$, a certain fraction of fatigue damage $\Delta D_{i}$ was accumulated. Let us assume that the degree of breakdown is the same for all load levels and each level of vibration stresses there is a limiting number of cycles-durability $N_{i}>n_{i}$, at which a crack (fracture) is likely to occur in the test piece [16-18], then the damage accumulated at the level vibration stress $\sigma_{i}$ is defined as:

$\Delta D_{i}=n_{i} / N_{i}$

At the final k-th the load level with the number of cycles $n_{k}$, a crack was formed in the test piece, which means that following the principle of linear damage summation, the damaging of the specimen accumulated at all levels reached its limiting value, taken equal to unity.

$D_{k}=\sum_{i=1}^{k} \frac{n_{i}}{N_{i}}=1$

To take into account the fraction of accumulated damage at the load level passed by the specimen, equation (1) is used, where the durability logarithm $\mathrm{N}_{\mathrm{i}}$ is determined by the following equations:

$\lg N_{i}^{\prime \prime}=\lg \left(N_{i}\right)_{0.9}^{\prime}+s$

or

$$
Y_{i}=\left(Y_{i}\right)_{0.9}^{\prime}+s
$$

in which $\left(Y_{i}\right)_{0.9}$-the number of cycles corresponding to the quantile fatigue curve for the fracture probability $P=0.9$ at the stress level $\sigma_{i}$; s-a constant (yet unknown) coefficient for all load levels of a given test piece. The coefficient $s$ is determined by substituting equation (5) into (4):

$\sum_{i=1}^{k} \frac{n_{i}}{{ }_{10} \lg \left(N_{i}\right)_{0.9}^{l}+s}=1$

where $n_{i}$-the number of cycles at the first (lower) stress level $\sigma_{1}$ exceeding the material endurance limit, i.e., $\sigma_{1}>\sigma_{-1}$; $n_{k}=N_{k}$ (failure at the k-th level), whence it follows the value: $s=\lg \left(\sum_{i=1}^{k} \frac{n_{i}}{\left(N_{i}\right)_{0.9}^{l}}\right)$

The second stage includes the determination of certain equivalent durability $\left(N_{e q}{ }^{\prime \prime \prime}\right)$, to determine which equation (7) is used, presenting it in a slightly different form.

$\frac{n_{1}}{{ }_{10} l g\left(N_{1}\right)_{0,9}^{\prime}}+\sum_{i=2}^{k} \Delta D_{i}=\frac{n_{1}+\Delta n_{1}^{\prime \prime}}{{ }_{10} \lg \left(N_{1}\right)_{0,9}^{\prime}+s}=\frac{\left(N_{1}\right)_{e q}^{\prime \prime \prime}}{{ }_{10} l g\left(N_{1}\right)_{0,9}^{\prime}+s}=1$

where $\Delta n_{1}$-the number of cycles that the specimen would pass at the first level of vibration stresses before the formation of the cracks. Equation (9) implies:

$\left(N_{1}\right)_{e q}^{\prime \prime \prime}=10^{\lg \left(N_{1}\right)_{0,9}^{\prime}+s}$

The third stage is carried out similarly to the first, with the replacement of the fatigue values for those obtained in the second stage, as well as with the exclusion of points with stress levels below the endurance limit [19-21]. The results of the regression analysis obtained during the third stage are shown in Figure 5. Test pieces for which the durability was recalculated are indicated by red dots. Thus, it turns out that the endurance limit $\sigma-1=480 \mathrm{MPa}$, determined from 7 undestroyed specimens, lies much closer to the fatigue curve with a fracture probability $P=0.1$. And with the probability of survival $P=0.9$ based on tests $N=2 \cdot 10^{7}$ cycles, the level of vibration stresses corresponds to $\sigma-1=470 \mathrm{MPa}$.

\section{CONCLUSIONS}

Hence, the use of the linear damage summation hypothesis in processing the results of fatigue tests entails a satisfactory practical accuracy of the calculation of endurance limit. From the analysis of the fatigue curves of the titanium alloy, it is shown that fracture occurs when the sample damage accumulated at all levels (for the number of cycles $n_{i}$ and the limit number of $i$-load cy-

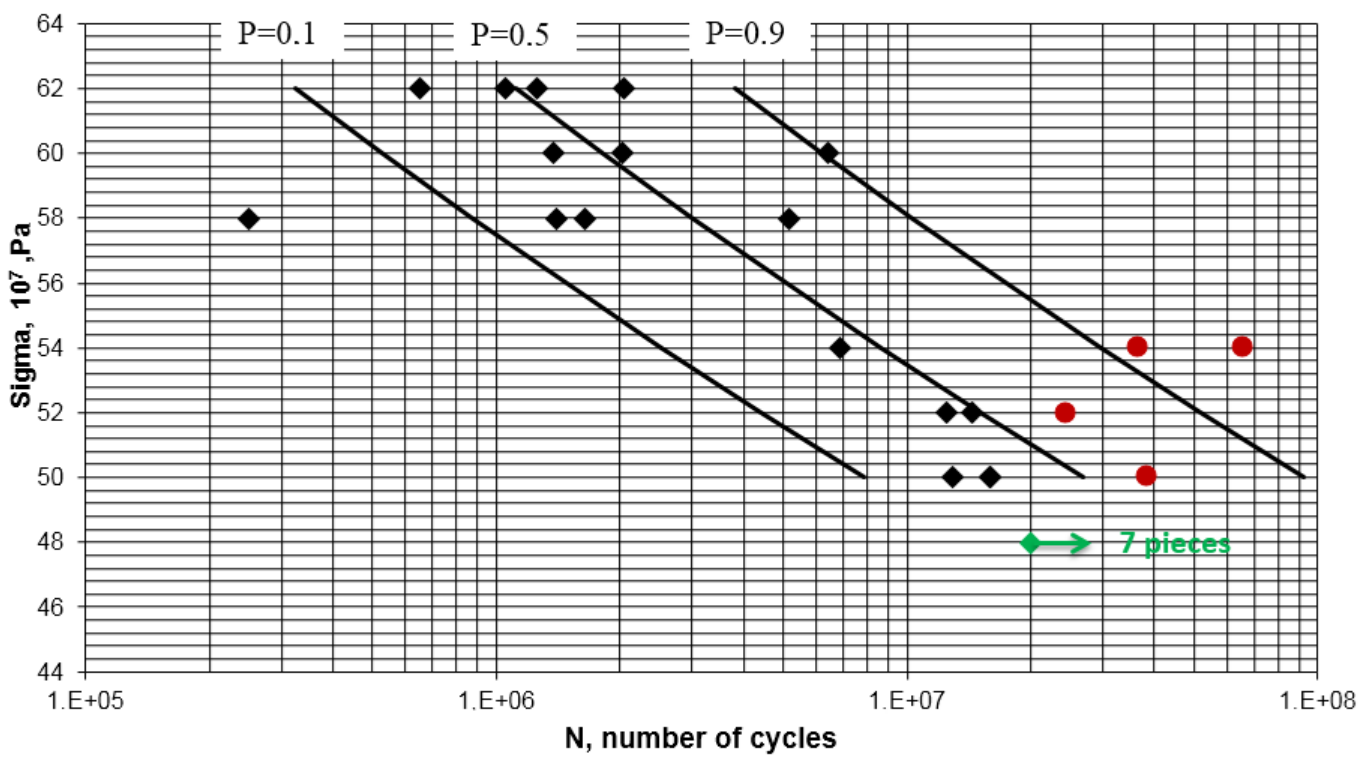

Figure 5: Fatigue curves for different fracture probabilities $P(0.1 ; 0.5 ; 0.9)$ after linear damage summation 
cles $N_{i}$ ) reaches its limiting value $\sum_{i=1}^{k} n_{i} / N_{i} \geq 1$. At the same time, during the experiments, there was no significant difference between the minimum and maximum loads, and there were also no sharp overloads. Also, the study did not reveal the effect of the sequence of stress and the loading history on the material durability. According to the test results, the endurance limit of titanium alloy has been determined, which lies in the range from 460 to $480 \mathrm{MPa}$. Thus, the results of the study showed that the hypothesis of linear damage summation is applicable for the material considered in question. The presented research is aimed at improving metal production by studying the quality of titanium alloy test pieces and performing mathematical analysis of possible problems arising in the process of its operational testing.

\section{ACKNOWLEDGEMENTS}

This study is conducted with financial support from the Ministry of Education and Science of the Russian Federation (project No. FZRR-2020-0023/code 0699-2020-0023).

\section{REFERENCES}

1. Hering, O., Tekkaya, A.E. (2020). Damage-induced performance variations of cold forged parts. Journal of Materials Processing Technology, vol. 279, article number 116556. DOI: 10.1016/j.jmatprotec.2019.116556

2. Sunder, R. (2016). Why and how residual stress affects metal fatigue. Springer Proceeding in Physics, vol. 175, 489-504. DOI: 10.1007/978-3-319-263243_34

3. Paul, S.K. (2020). Correlation between endurance limit and cyclic yield stress determined from low cycle fatigue test. Materialia, vol. 11, article number 100695. DOI: 10.1016/j.mtla.2020.100695

4. Li, P., Warner, D.H., Fatemi, A., Phan, N. (2016). Critical assessment of the fatigue performance of additively manufactured Ti-6AL-4V and perspective for future research. International Journal of Fatigue, vol. 85, 130-143. DOI: 10.1016/j.jfatigue.2015.12.003

5. Zhu, S.P., Yue, P., Yu, Z.Y., Wang, Q. (2017). A combined high and low cycle fatigue model for life prediction of turbine blades. Materials, vol. 10, 80-98. DOI: 10.3390/ma10070698

6. Gates, N.R., Fatemi, A. (2017). On the consideration of normal and shear stress interaction in multiaxial fatigue damage analysis. International Journal of Fatigue, vol. 100, 322-336. DOI: 10.1016/j.ijfatigue.2017.03.042

7. Yoshinaka, F., Nakamura, T., Takeuchi, A., Uesugi, M., Uesugi, K. (2019). Initiation and growth behaviour of small internal fatigue cracks in Ti-6Al-4V via synchrotron radiation microcomputed tomography. Fatigue and Fracture of Engineering Materials and Structures, vol. 42, no. 9, 2093-2105. DOI: $10.1111 / \mathrm{ffe} .13085$
8. He, Y., Xiao, G., Li, W., Huang, Y. (2018). Residual stress of a titanium alloy after belt grinding and its impact on the fatigue life. Materials, vol. 11, 155-189. DOI: $10.3390 / \mathrm{ma} 11112218$

9. Shojaei, A.K., Volgers, P. (2017). Fatigue damage assessment of unfilled polymers including self-heating effects. International Journal of Fatigue, vol. 100, 367-376. DOI: 10.1016/j.ijfatigue.2017.03.017

10. Mughrabi, H. (2015). Microstructural mechanisms of cyclic deformation, fatigue crack initiation and early crack growth. Philosophical Transactions of the Royal Society A: Mathematical, Physical and Engineering Sciences, vol. 373, 1-21. DOI: 10.1098/ rsta.2014.0132

11. Pineau, A., McDowell, D.L., Busso, E.P., Antolovich, S.D. (2016). Failure of metals II: Fatigue. Acta Materialia, vol. 107, 484-507. DOI: 10.1016/j.actamat.2015.05.050

12. Yang, K., Zhong, B., Huang, Q., He, C. (2018). Stress ratio effect on notched fatigue behavior of a Ti-8Al-1Mo-1V alloy in the very high cycle fatigue regime. International Journal of Fatigue, vol. 116, 8089. DOI: 10.1016/j.ijfatigue.2018.05.032

13. Stanzl-Tschegg, S. (2014). Very high cycle fatigue measuring techniques. International Journal of Fatigue, vol. 60, 2-17. DOI: 10.1016/j.ijfatigue.2012.11.016

14. Antolovich, S.D., Armstrong, R.W. (2014). Plastic strain localization in metals: Origins and consequences. Progress in Materials Science, vol. 59, 1-160. DOI: 10.1016/j.pmatsci.2013.06

15. Maurel, P., Weiss, L., Grosdidier, T., Bocher, P. (2020). How does surface integrity of nanostructured surfaces induced by severe plastic deformation influence fatigue behaviors of Al alloys with enhanced precipitation? International Journal of Fatigue, vol. 140, article number 105792. DOI: 10.1016/j.ijfatigue.2020.105792

16. Debroy, T., Wei, H.L., Zuback, J.S., Elmer, J.W., Beese, A.M., Zhang, W. (2018). Additive manufacturing of metallic components - Process, structure and properties. Progress in Materials Science, vol. 92, 112-224. DOI: 10.1016/j.pmatsci.2017.10.001

17. Kumar, S., Chattopadhyay, K., Singh, V. (2017). Effect of ultrasonic shot peening on LCF behavior of the Ti-6Al-4V alloy. Journal of Alloys and Compounds, vol. 724, 187-197. DOI: 10.1016/j.jallcom.2017.07.014

18. Ding, D., Pan, Z., Cuiuri, D., Li, H. (2015). Wirefeed additive manufacturing of metal components: technologies, developments and future interests. International Journal of Advanced Manufacturing Technology, vol. 81, no. 1-4, 465-481. DOI: 10.1007/ s00170-015-7077-3 
19. Liu, C., Liu, D., Zhang, X., Ma, A., Ao, N., Xu, X. (2019). Improving fatigue performance of Ti-6Al-4V alloy via ultrasonic surface rolling process. Journal of Materials Science and Technology, vol. 35, 15551562. DOI: 10.1016/j.jmst.2019.03.036

20. Su, B., Zhang, Y., Sun, G., Ni, Z. (2018). Prediction of micro indention depth of titanium alloy during laser shock processing. Japanese Journal of Applied Physics, vol. 57, 122-137. DOI: 10.7567/JJAP. 57.122703
21. Xiao, H., Fan, X.G., Zhan, M., Liu, B.C., Zhang, Z.Q. (2021). Flow stress correction for hot compression of titanium alloys considering temperature gradient induced heterogeneous deformation. Journal of Materials Processing Technology, vol. 288, article number 116868. DOI: 10.1016/j.jmatprotec.2020.116868 